\title{
Management of mantle cell lymphoma in the elderly patient
}

\author{
This article was published in the following Dove Press journal: \\ Clinical Interventions in Aging \\ 13 September 2013 \\ Number of times this article has been viewed
}

\author{
Jeanette K Doorduijn' \\ Hanneke C Kluin- \\ Nelemans ${ }^{2}$ \\ 'Department of Hematology, Erasmus \\ MC, Rotterdam, The Netherlands; \\ ${ }^{2}$ Department of Hematology, \\ University Medical Center Groningen, \\ University of Groningen, Groningen, \\ The Netherlands
}

\begin{abstract}
Mantle cell lymphoma is a relatively rare B-cell lymphoma with a specific genetic lesion and a typical immunophenotypic profile. The median age is 65 years. There is no curative treatment, except allogeneic stem cell transplantation for a selected group of patients. For the majority of patients, especially the elderly, the aim of therapy should therefore be a long progression-free survival. Age and comorbidity may hamper the use of the most active treatment regimen, such as high dose cytarabine and autologous stem cell transplantation. Therefore, it is a challenge to select the most appropriate therapy for an elderly patient. Studies specifically designed for elderly patients are rare. A recently performed large randomized study for elderly patients, however, has shown that R-CHOP (rituximab with cyclophosphamide, doxorubicin, vincristine, and prednisone) chemotherapy followed by maintenance rituximab can result in a long progression-free survival. For patients too frail for R-CHOP chemotherapy, a treatment should be offered that benefits the patient in reducing the symptoms of the disease without causing too many side effects. Progression or relapse will occur in all patients sooner or later. Second-line treatment should again be carefully selected. Several options are mentioned. New drugs are being developed, and new combinations are investigated. Further improvement in the outcome of patients with mantle cell lymphoma is expected. Participation in well-designed clinical trials, also by elderly patients, is important to find the real benefit that can be achieved, and to get information on the tolerability of these treatments in this age group.
\end{abstract}

Keywords: treatment, chemotherapy, malignant lymphoma, mantle cell lymphoma, elderly, MCL

\section{Introduction}

Malignant lymphoma, or non-Hodgkin's lymphoma, is not a single disease, but a name for a group of different disease entities that originate from mature lymphocytes. Histologic, immunologic, and genetic features are used to discriminate the different entities. In the World Health Organization classification of hematological malignancies, the lymphomas are described in the chapters on mature B- and T-cell neoplasms. ${ }^{1}$

Mantle cell lymphoma (MCL) is one of the well-recognized B-cell lymphomas. It has a specific genetic lesion, and a characteristic immunophenotype. It is relatively rare, comprising $5 \%-7 \%$ of the lymphomas. ${ }^{2}$ More than $50 \%$ of patients is 65 years or older. There is a striking male predominance, with $60 \%-70 \%$ of the patients being male. MCL has some typical clinical features. It used to have a poor prognosis, but in recent years the outcome of treatment has shown major improvements. ${ }^{3}$
Correspondence: Jeanette K Doorduiin Erasmus MC, Doctor Molewaterplein 50-60, Rotterdam, The Netherlands Email j.doorduijn@erasmusmc.nl 


\section{Pathology}

The diagnosis of a malignant lymphoma cannot be made without an adequate biopsy, preferably from a lymph node. MCL typically shows a proliferation of monotonous small or medium sized lymphocytes with inconspicuous nucleoli. In a minority of cases, a blastoid variant is present. In these cases, the malignant cells are larger, have multiple nucleoli, and a high proliferation rate, and a diffuse large B-cell lymphoma might be mistakenly suspected. Immunohistochemically, MCL cells express the B-cell markers CD79b and CD20. Typical for MCL is the co-expression of the T-cell marker CD5. The co-expression of CD5 is also common in chronic lymphocytic leukemia (CLL). To make the distinction between MCL and CLL, CD23 is an important marker: in MCL, CD23 is usually not positive, whereas in CLL, there is co-expression of CD5 and CD23. ${ }^{1}$

The genetic lesion in MCL is a translocation between chromosome 11 and chromosome 14, t(11;14)(q13; 32 ). The proto-oncogene CCND1 on chromosome 11q13 is continuously activated by the Ig heavy chain gene on $14 q 32$. This results in the overexpression of cyclin D1 mRNA, resulting in continuous cell proliferation. The protein cyclin D1 can be easily demonstrated by immunohistochemistry, and is the hallmark of MCL. Only in rare cases, MCL is cyclin D1 negative. This might be suspected if other features, such as morphology and immunology are typical for classical MCL. In these cases, cyclin D2 or cyclin D3 can be overexpressed. ${ }^{4}$

Thus the typical immunohistochemical features are CD5 positive, CD23 negative, and cyclin D1 positive. The proliferation marker Ki-67 shows a variable expression.

\section{Staging}

When the diagnosis of a malignant lymphoma has been made, it is important to investigate the localizations of disease. The results will influence treatment, and are important for response assessment. Most patients with MCL present with advanced disease, with a generalized lymphadenopathy. Moreover, MCL tends to spread to extranodal localizations, ie, bone marrow, liver, skin, or gastrointestinal. The gastrointestinal localization can occasionally present as multiple intestinal polyposis. Only a minority of patients with gastrointestinal localization have symptoms. ${ }^{5}$ Massive splenomegaly is not uncommon. Bone marrow examination shows MCL infiltration in the majority of patients. In up to $25 \%$ of cases, the disease is leukemic, with MCL cells circulating in the peripheral blood. Therefore, a distinction with CLL should be made (see above). Flow cytometry of the peripheral blood will detect MCL cells in a much higher frequency than by morphology only. ${ }^{6}$
Later in the course of the disease, MCL infiltration can be observed in otherwise rarely affected localizations, such as the central nervous system..$^{7-9}$

The staging procedure includes physical examination, blood count, lactate dehydrogenase, computed tomography scan of neck, thorax, abdomen, and pelvis, and a bone marrow aspiration and biopsy. Flow cytometry of the bone marrow is advised. An FDG-PET (fluorodeoxyglucose-enhanced positron emission tomography) scan is still considered investigational. ${ }^{10}$ The sensitivity of FDG-PET for extranodal localizations is low. ${ }^{11}$ A negative end-of-treatment scan has a high negative predictive value for relapse, but does not predict for better survival. False-positive PET scans are not uncommon.

Examination of cerebrospinal fluid, both morphologic and by flow cytometry, should be performed in the case of neurologic complaints. If gastrointestinal symptoms are present, a gastroscopy or colonoscopy should be considered.

The results of the staging procedures are used for the classification in four staging groups, according to the Ann Arbor classification (Table 1). ${ }^{12}$ Systemic symptoms defined as fever without definitive cause, night sweats, or more than $10 \%$ weight loss in less than 6 months are mentioned in the Ann Arbor classification as B-symptoms.

\section{Prognosis}

MCL has a gradually or rapidly progressive course. Real indolent cases, showing no progression for many years, are recognized, but rare. The typical clinical presentation of this indolent subgroup usually is a marked leukocytosis and splenomegaly, in the absence of lymphadenopathy. ${ }^{13}$

Table I Ann Arbor classification

\begin{tabular}{|c|c|}
\hline Stage & Definition \\
\hline \multicolumn{2}{|l|}{ I } \\
\hline I & Involvement of a single lymph node region or \\
\hline IE & a single extranodal site \\
\hline \multicolumn{2}{|l|}{ II } \\
\hline II & $\begin{array}{l}\text { Involvement of two or more lymph node regions on the same } \\
\text { side of the diaphragm or }\end{array}$ \\
\hline IIE & $\begin{array}{l}\text { localized involvement of an extralymphatic site in combination } \\
\text { with one or more lymph node regions on the same side of the } \\
\text { diaphragm }\end{array}$ \\
\hline \multicolumn{2}{|l|}{ III } \\
\hline III & Involvement of lymph node regions on both side of the diaphragm \\
\hline IIIS & with infiltration of spleen or \\
\hline IIIE & with localized involvement of an extralymphatic site or \\
\hline IIIES & $\begin{array}{l}\text { with infiltration of spleen and localized involvement of an } \\
\text { extralymphatic site }\end{array}$ \\
\hline IV & $\begin{array}{l}\text { Diffuse or disseminated infiltration of one or more extralymphatic } \\
\text { organs or tissues, with or without lymphadenopathy }\end{array}$ \\
\hline
\end{tabular}


Aside from this rare subgroup, most patients need therapy to reduce symptoms, or to prevent deteriorating disease. Patients with a blastoid variant of MCL are more likely to have a rapidly progressive course, and a poor response on chemotherapy.

In MCL, several clinical factors are recognized that influence the prognosis. The MIPI (MCL International Prognostic Index) score has been developed based upon clinical factors that are present at diagnosis. The clinical risk factors that negatively influence outcome are: higher age, performance status $>1$, higher lactate dehydrogenase, and higher leucocyte count. With these variables, the score can be calculated that stratifies the patients into three groups. The median overall survival (OS) in the good prognosis group was not reached; in the intermediate group, 51 months; and in the poor prognosis group, 29 months. For clinical practice, a simplified MIPI is suggested. ${ }^{14}$

The proliferation rate of the cells is another prognostic factor. ${ }^{15,16}$ The pathologist can determine the proliferation rate with the Ki-67 antibody. In the MIPIb (combined biological index), the percentage of $\mathrm{Ki}-67$-positive cells is incorporated. ${ }^{14}$

\section{Therapy of newly diagnosed MCL, general principles}

Treatment of patients with MCL used to result in a poor outcome, with a 5 -year OS of $27 \% .^{2}$ However, the median OS has changed over the last decade, by introduction of new therapeutic options. Because of these new evolving therapeutic options, there is no standard treatment regimen for MCL, as new studies are continuously showing further improvements.

The first major improvement has been the introduction of the anti-CD20 monoclonal antibody rituximab, in combination with the standard CHOP (cyclophosphamide, doxorubicin, vincristine, and prednisone) regimen. The complete remission rate improved, and the progression-free survival (PFS) observed after R-CHOP (rituximab with CHOP) treatment was 18 months, although this did not seem to improve the OS. ${ }^{17,18}$ A meta-analysis of randomized controlled trials, including $260 \mathrm{MCL}$ patients, indicated a survival benefit in patients treated with immunochemotherapy compared with chemotherapy only. ${ }^{19}$ The important role of rituximab has not only been observed in clinical trials and meta-analysis, but also in an observational populationbased study. The addition of rituximab in this study has resulted in an improvement of median survival from 27 to 37 months. $^{20}$
The introduction of high dose cytarabine (Ara-C) in the treatment of MCL has been another change resulting in a better outcome. Several regimens are used. ${ }^{21-24}$

Finally, consolidation with autologous transplantation was shown to prolong survival of MCL patients. ${ }^{25}$ The conditioning regimen before the autologous transplantation might be intensive chemotherapy, ie, BEAM (consisting of bis-chloroethylnitrosourea, etoposide, cytarabine, and melphalan) or include total body irradiation. ${ }^{26,27}$

Only a minority of MCL patients have stage I disease. Patients with stage I disease have been excluded from most clinical trials, assuming that limited chemotherapy followed by local radiotherapy as in stage I diffuse large B-cell lymphoma is very effective. However, this has not been formally studied in a randomized trial. A retrospective study in $26 \mathrm{MCL}$ patients with stage I or II disease showed the importance of radiotherapy in limited disease..$^{28}$ Patients receiving radiotherapy as part of the induction therapy had a significantly better 5-year PFS: $73 \%$ versus $13 \%$ without radiotherapy. There was a trend for better PFS in stage I compared to stage II disease (5-year PFS, 73\% versus 20\%). Although the numbers were small, the authors concluded that limited cycles of multi-agent chemotherapy with radiotherapy might be the treatment of choice in this group of patients. A recent retrospective study confirmed the better outcome of stage I compared with stage II patients, with combined modality treatment. The 5-year PFS was 44\%; the 5-year OS, $62 \% .^{29}$

\section{Treatment of elderly patients}

For many elderly patients, an intensive treatment with high dose cytarabine and transplantation is too toxic. There is no clear definition of elderly in this respect. Arbitrarily, clinical trials often use a cutoff of 65 years or older. However, even some patients less than 65 might be considered as elderly, in the case of cardiac disease or other comorbidity. With a median age of 65 years at diagnosis of MCL, half of the patients are not eligible for the "standard" therapy with autologous transplantation. However, even with a less intensive treatment the outcome of the fit elderly patient has improved by incorporating rituximab and maintenance therapy.

Studies investigating minimal residual disease have shown that those patients achieving a molecular complete remission after therapy have a low risk of early progression, and in general have a long event-free survival. It is therefore important to try to obtain a complete remission, also for elderly patients. ${ }^{30}$ 
The backbone of therapy is R-CHOP. This regimen is repeated every 3 weeks, up to eight courses. The result is generally a reduction of lymphadenopathy and other symptoms. Overall responses (complete and partial remissions combined) of approximately $85 \%$ can be obtained. A complete remission (CR), no signs of disease left on computed tomography scan and other restaging procedures, is achieved in $30 \%-40 \%$ of patients. ${ }^{18,31}$ Relapse or progression is common after $2-3$ years. ${ }^{18}$

The European MCL Network designed a study that aimed to improve the results of induction therapy, and to prolong the duration of remission. In this randomized, multicenter study, the standard R-CHOP, eight cycles, was compared with rituximab, the purine analog fludarabine, and cyclophosphamide (R-FC), every 4 weeks, a total of six cycles. The responding patients were randomized between maintenance therapy with interferon-alpha or rituximab. This maintenance treatment was planned to continue until progression. ${ }^{31}$ In almost 7 years, 560 patients from eight countries were randomized. The median age was 70 years. The results were unexpected. The new induction regimen R-FC did not improve the outcome; in both treatment arms the response rate (partial response and complete response) was not statistically different: after R-CHOP $86 \%$, after R-FC $78 \%$. The CR rate was $34 \%$ and $40 \%$ respectively, also not statistically different. The OS in the R-CHOPtreated patients was better than in the R-FC-treated patients, the survival rate after 4 years being $62 \%$ versus $47 \%$. The toxicity of R-FC was more severe, especially hematologic toxicity, and infections were observed more frequently.

The outcome of the maintenance treatment was very much in favor of rituximab. After 4 years, $58 \%$ of the patients had not shown progression or relapse, compared with $29 \%$ of the patients that started interferon maintenance. This resulted in a 4-year OS in the patients treated with R-CHOP and rituximab maintenance of almost $85 \%$. Eight cycles of R-CHOP followed by rituximab maintenance therefore now is considered the standard treatment for elderly patients with MCL, until a new study will hopefully show further improved outcome data.

An alternative alkylating agent is bendamustine. This agent has been used for the treatment of indolent lymphomas and MCL in Germany for more than 20 years, but was only approved in Europe and US a few years ago. In a recently randomized study in patients with indolent lymphoma or MCL, R-CHOP has been compared with R-bendamustine. ${ }^{32}$ The study was designed as a noninferiority trial. The toxicity of R-bendamustine was lower, except for skin rash. Erythema or allergic reactions of the skin were observed in $31 \%$ of the patients, compared with $15 \%$ after R-CHOP. Ninety-four patients in this study (18\%), with a median age of 70 years, were diagnosed with a MCL. The median PFS of the MCL patients was 35 months with R-bendamustine, compared with 22 months after R-CHOP. No difference in OS has been observed, however. A second study, not yet published, for indolent lymphomas including MCL, has been initiated in the USA. In this study, R-bendamustine is being compared with R-CHOP or R-CVP (rituximab with cyclophosphamide, vincristine, and prednisone).

\section{Treatment of the frail elderly patient}

For the frail elderly patient, therapy should aim to reduce symptoms and maintain quality of life. Usually, the very elderly patient, or the patient with severe comorbidity, cannot be treated with R-CHOP. A less intensive regimen should be selected to reduce symptoms. In some patients, R-CVP might be feasible: doxorubicin is responsible for many of the side effects of R-CHOP, ie, nausea and vomiting and neutropenia. There is no risk to further reduction of cardiac function without the administration of doxorubicin.

An alternative for the frail elderly is oral chlorambucil that might be combined with rituximab. This is a welltolerated regimen in most patients. ${ }^{33}$

The results of monotherapy rituximab are not very impressive. An overall response rate of $27 \%$ has been observed, with an event-free survival of 6 months, which is less than can be obtained in follicular lymphoma. Longer treatment did not significantly improve the outcome. ${ }^{34}$

Finally, in the case of localized symptomatic lymphadenopathy, local control can be obtained by radiotherapy. ${ }^{35}$

\section{Therapy of relapsed or progressive elderly MCL patients}

Although the results of upfront treatment have improved, finally patients will show relapse or progressive disease. There is no standard therapy for relapse or progression. Several options are mentioned as follows (overview in Table 2). Most of the studies with relapsed/refractory patients are not specifically designed for elderly patients, but most of them have included elderly patients as well, as is reflected in the median age.

Rituximab/bendamustine is an active regimen for MCL, and can be used in the relapsed setting. ${ }^{36}$ Retreatment with bendamustine is possible, although no details are known 
Table 2 Overview of optional therapy choices for elderly patients with relapsed or refractory mantle cell lymphoma

\begin{tabular}{|c|c|c|c|c|c|}
\hline Publication & Regimen & $\mathbf{N}$ & Responses & Median response duration & Median age (years) \\
\hline \multirow[t]{2}{*}{ Rummel et $\mathrm{al}^{36}$} & BR (bendamustine, rituximab) & 16 & ORR $75 \%$ & PFS I8 months & 66 \\
\hline & & & CR $50 \%$ & & \\
\hline \multirow[t]{2}{*}{ Weide et $\mathrm{al}^{38}$} & BMR (bendamustine, mitoxantrone, & 18 & ORR $77 \%$ & PFS 21 months & 66 \\
\hline & rituximab) & & CR $33 \%$ & OS at 2 years $60 \%$ & \\
\hline \multirow[t]{2}{*}{ Thomas et $\mathrm{al}^{39}$} & FC (fludarabine, cyclophosphamide) & 16 & ORR $75 \%$ & TTF II months & 65 \\
\hline & & & CR $56 \%$ & & \\
\hline \multirow[t]{2}{*}{ Forstpointner et al ${ }^{40}$} & R-FCM (rituximab, fludarabine, & 24 & ORR $58 \%$ & PFS 8 months & 65 \\
\hline & cyclophosphamide, mitoxantrone) & & CR 29\% & OS at 2 years $65 \%$ & \\
\hline \multirow[t]{2}{*}{ Visco et $\mathrm{a}^{42}$} & R-BAC (rituximab, bendamustine, & 20 & ORR $80 \%$ & PFS at 2 years $70 \%$ & 70 \\
\hline & cytarabine) & & CR $70 \%$ & & \\
\hline \multirow[t]{2}{*}{ Inwards et al ${ }^{43}$} & Cladribine & 24 & ORR $46 \%$ & PFS 5.4 months & 68 \\
\hline & & & CR $21 \%$ & OS at 2 years $36 \%$ & \\
\hline \multirow[t]{2}{*}{ Fisher et al ${ }^{14}$} & Bortezomib & 155 & ORR $33 \%$ & DR 9.2 months & 65 \\
\hline & & & CR $8 \%$ & OS not reached & \\
\hline \multirow[t]{2}{*}{ Hess et al ${ }^{50}$} & Temsirolimus & 108 & ORR $22 \%$ & PFS 4.8 months & 68 \\
\hline & & & CR $2 \%$ & OS I 2.8 months & \\
\hline \multirow[t]{2}{*}{ Habermann et al ${ }^{52}$} & Lenalidomide & 15 & ORR $53 \%$ & PFS 5.6 months & 66 \\
\hline & & & CR $20 \%$ & DR I3.7 months & \\
\hline \multirow[t]{2}{*}{ Weigert et a $\mathrm{a}^{47}$} & R-HAD + B (rituximab, cytarabine, & 8 & ORR $50 \%$ & PFS 5.5 months & 65 \\
\hline & dexamethasone, bortezomib) & & CR $25 \%$ & OS 15 months & \\
\hline
\end{tabular}

Abbreviations: ORR, overall response rate; CR, complete response rate; PFS, progression-free survival; TTF, time to treatment failure; DR, duration of response; OS, overall survival.

about its effectiveness in MCL. ${ }^{37}$ Combination therapy with mitoxantrone may be an option. ${ }^{38}$

Fludarabine/cyclophosphamide (FC) is also active in relapsed MCL. ${ }^{39}$ The combination rituximab, fludarabine, cyclophosphamide, and mitoxantrone (R-FCM) can result in a response rate of 58\%-79\% ${ }^{40,41}$ However, R-FCM is not suitable for patients who have received CHOP because of the cumulative cardiac anthracycline toxicity. Maintenance rituximab does not significantly improve the response duration but increases the number of patients with remissions beyond 2 years. ${ }^{41}$

The major side effect of fludarabine-containing regimens is hematologic toxicity. In the upfront setting, R-FC was inferior compared with R-CHOP, mainly caused by increased toxicity. ${ }^{31}$ However, fludarabine is an effective drug in the treatment of MCL, and it might be considered in the relapse setting. It is important to select the fitter patients for this treatment.

Most elderly patients have not received high dose cytarabine in first-line treatment. There are some data that show a reduced dose cytarabine is also effective. This might be considered in the relapse setting. In a Phase II study in elderly patients, the combination rituximab, bendamustine, and cytarabine (R-BAC) has been explored. Twenty patients had been previously treated. The R-BAC regimen was effective, but had a high rate of myelosuppression. A new study with a lower dose of cytarabine has been started. ${ }^{42}$
Monotherapy with the purine nucleoside analog cladribine has shown some activity in relapsed MCL, with relatively low toxicity ${ }^{43}$

In the US, the proteasome inhibitor bortezomib has been approved for the treatment of relapsed or progressive MCL. Activation of the nuclear factor kappa B (NF- $\kappa B)$ is an important result of the activated proliferation pathway in MCL. Bortezomib has been shown to inhibit NF- $\mathrm{\kappa B}$ activation. Monotherapy with bortezomib can result in a response rate of $30 \%-45 \%$, but a median PFS of only 6 months. ${ }^{44,45}$ The major side effect of bortezomib is neuropathy, either a sensory neuropathy or neuropathic pain. With the recently introduced use of subcutaneous instead of intravenous administration, the risk of neuropathy has decreased.$^{46}$ Combination of bortezomib with cytarabine has also been explored, and seems feasible with a dose adjustment for elderly patients. ${ }^{47}$

In Europe, temsirolimus, an mTOR (mammalian target of rapamycin) kinase inhibitor, is approved for relapsed MCL. In the PI3K/AKT pathway, which plays a major role in the proliferation of MCL, mTOR is one of the regulatory proteins. So it seemed attractive to investigate this drug in relapsed MCL. In relapsed/refractory MCL, single-agent temsirolimus achieves a response in $40 \%$ of patients, with only $3 \%$ complete remissions, however. The median duration of response is only 6 months. ${ }^{48,49}$ In a randomized Phase III study, temsirolimus has been compared to single-agent 
physician's choice therapy. Again, in a heavily pretreated group of patients, with a median of three previous lines of therapy (range 2-7), the PFS with temsirolimus monotherapy was only 5 months. The major toxicities of temsirolimus are thrombocytopenia, diarrhea, and asthenia. ${ }^{50}$

Lenalidomide, an immunomodulatory drug that is active in several B-cell malignancies, has been studied in relapsed MCL. The reported response rates are $42 \%-55 \%$, with a PFS of 6 months. ${ }^{51,52}$ To date, no randomized studies with lenalidomide have been performed in MCL, but these results are promising.

In a selective group of younger patients, an allogeneic transplantation may be considered after successful reinduction therapy. An allogeneic transplantation is the only curative option, but the treatment-related mortality is considerable, up to $30 \%$. Acute and chronic graft versus host disease is common, and has a major impact on quality of life. ${ }^{53}$

In elderly patients an allogeneic transplantation will rarely be the choice of therapy.

In a palliative setting, radiotherapy is an attractive option to treat symptoms resulting from enlarged lymph nodes. MCL is radiosensitive, so radiotherapy is useful to achieve local control. ${ }^{35}$

\section{New developments}

In young patients, both R-DHAP (rituximab with dexamethasone, cytarabine, and cisplatin) or single-agent high dose cytarabine have been used successfully to improve outcome. Based on these results, it seems attractive to explore whether an induction regimen with cytarabine is also feasible in elderly patients. Improvement of the response rate, and especially the CR-rate, could lead more patients to maintenance therapy, and further improve outcome.

Although the R-DHAP regimen is considered too toxic for most elderly patients, a modification might result in acceptable toxicity and still be effective. Some experience in relapsed patients is promising. The European MCL Network will initiate a new randomized study to investigate a cytarabine-based treatment in elderly patients.

Several other drugs have shown promising results in MCL, and are being studied.

Lenalidomide is an immunomodulatory drug, which is very active and widely used in the treatment of multiple myeloma, both in induction and maintenance therapy. It has shown promising results in MCL, as mentioned before. It is an oral agent, with limited side effects, and therefore very attractive for use in the maintenance setting. The European MCL Network will investigate the role of lenalidomide as a maintenance treatment in its next elderly study.

New small molecule drugs are being developed with novel mechanisms of action.

The PI3K/AKT/mTOR pathway is subject to the development of new active drugs. A constitutive activation of this pathway results in survival of the tumor cells. PI3K delta is inhibited by idelalisib, GS1101 (formerly CAL-101). This drug has shown clinical activity in relapsed MCL. More clinical studies have been performed in CLL. There is a good clinical activity, but up to $5 \%$ of the patients develop severe liver enzyme disturbances.

Some other agents that inhibit signal transduction components of the B-cell receptor pathway had disappointing results in early clinical trials. Fostamatinib, a SYK inhibitor, was not very active in a Phase I/II study. ${ }^{54}$ Enzastaurin, a protein kinase $\mathrm{C}$ beta (PKC- $\beta$ ) inhibitor, induced no response in a Phase II study with 60 patients. The median time to progression was 2 months. ${ }^{55}$

The B-cell receptor signaling pathway is activated in many B-cell malignancies. Bruton's tyrosine kinase (BTK) is essential in this pathway. A new BTK-inhibitor, ibrutinib, shows very promising results in early trials in MCL. This oral agent is non-myelosuppressive and seems a breakthrough in the treatment of CLL and MCL. Phase III studies are initiated and currently accruing patients. ${ }^{56-58}$

\section{Conclusion}

MCL is a malignant lymphoma that has shown major improvement in outcome, both in younger and elderly patients. However, relapses occur sooner or later. Several promising agents are being developed. It is of importance that patients, also those of high age, are encouraged to participate in clinical trials, to investigate the role of new treatment approaches and new drugs.

\section{Disclosure}

The authors report no conflicts of interest in this work.

\section{References}

1. Swerdlow SH, Campo E, Harris NL, et al. WHO Classification of Tumours of Haematopoietic and Lymphoid Tissues. Lyon: IARC; 2008.

2. A clinical evaluation of the International Lymphoma Study Group classification of non-Hodgkin's lymphoma. The NonHodgkin's Lymphoma Classification Project. Blood. 1997;89(11): 3909-3918.

3. Herrmann A, Hoster E, Zwingers T, et al. Improvement of overall survival in advanced stage mantle cell lymphoma. J Clin Oncol. 2009;27(4): $511-518$ 
4. Fu K, Weisenburger DD, Greiner TC, et al. Cyclin D1-negative mantle cell lymphoma: a clinicopathologic study based on gene expression profiling. Blood. 2005;106(13):4315-4321.

5. Romaguera JE, Medeiros LJ, Hagemeister FB, et al. Frequency of gastrointestinal involvement and its clinical significance in mantle cell lymphoma. Cancer. 2003;97(3):586-591.

6. Ferrer A, Salaverria I, Bosch F, et al. Leukemic involvement is a common feature in mantle cell lymphoma. Cancer. 2007;109(12): 2473-2480.

7. Ferrer A, Bosch F, Villamor N, et al. Central nervous system involvement in mantle cell lymphoma. Ann Oncol. 2008;19(1):135-141.

8. Gill S, Herbert KE, Prince HM, et al. Mantle cell lymphoma with central nervous system involvement: frequency and clinical features. Br J Haematol. 2009;147(1):83-88.

9. Conconi A, Franceschetti S, Lobetti-Bodoni C, et al. Risk factors of central nervous system relapse in mantle cell lymphoma. Leuk Lymphoma. Epub February 20, 2013.

10. Cheson BD, Pfistner B, Juweid ME, et al. Revised response criteria for malignant lymphoma. J Clin Oncol. 2007;25(5):579-586.

11. Hosein PJ, Pastorini VH, Paes FM, et al. Utility of positron emission tomography scans in mantle cell lymphoma. Am J Hematol. 2011;86(10):841-845.

12. Carbone PP, Kaplan HS, Musshoff K, Smithers DW, Tubiana M. Report of the committee on Hodgkin's disease staging classification. Cancer Res. 1971;31(11):1860-1861.

13. Orchard J, Garand R, Davis Z, et al. A subset of $t(11 ; 14)$ lymphoma with mantle cell features displays mutated $\mathrm{IgVH}$ genes and includes patients with good prognosis, nonnodal disease. Blood. 2003;101(12): 4975-4981.

14. Hoster E, Dreyling M, Klapper W, et al. A new prognostic index (MIPI) for patients with advanced-stage mantle cell lymphoma. Blood. 2008;111(2):558-565.

15. Determann O, Hoster E, Ott G, et al. Ki-67 predicts outcome in advanced-stage mantle cell lymphoma patients treated with anti-CD20 immunochemotherapy: results from randomized trials of the European MCL Network and the German Low Grade Lymphoma Study Group. Blood. 2008;111(4):2385-2387.

16. Klapper W, Hoster E, Determann O, et al. Ki-67 as a prognostic marker in mantle cell lymphoma-consensus guidelines of the pathology panel of the European MCL Network. J Hematop. 2009;2(2): 103-111.

17. Howard OM, Gribben JG, Neuberg DS, et al. Rituximab and CHOP induction therapy for newly diagnosed mantle-cell lymphoma: molecular complete responses are not predictive of progression-free survival. J Clin Oncol. 2002;20(5):1288-1294.

18. Lenz G, Dreyling M, Hoster E, et al. Immunochemotherapy with rituximab and cyclophosphamide, doxorubicin, vincristine, and prednisone significantly improves response and time to treatment failure, but not long-term outcome in patients with previously untreated mantle cell lymphoma: results of a prospective randomized trial of the German Low Grade Lymphoma Study Group (GLSG). J Clin Oncol. 2005;23(9):1984-1992.

19. Schulz H, Bohlius JF, Trelle S, et al. Immunochemotherapy with rituximab and overall survival in patients with indolent or mantle cell lymphoma: a systematic review and meta-analysis. J Natl Cancer Inst. 2007;99(9):706-714.

20. Griffiths R, Mikhael J, Gleeson M, Danese M, Dreyling M. Addition of rituximab to chemotherapy alone as first-line therapy improves overall survival in elderly patients with mantle cell lymphoma. Blood. 2011;118(18):4808-4816.

21. Khouri IF, Romaguera J, Kantarjian H, et al. Hyper-CVAD and highdose methotrexate/cytarabine followed by stem-cell transplantation: an active regimen for aggressive mantle-cell lymphoma. J Clin Oncol. 1998;16(12):3803-3809.

22. van 't Veer MB, de Jong D, MacKenzie M, et al. High-dose Ara-C and beam with autograft rescue in R-CHOP responsive mantle cell lymphoma patients. Br J Haematol. 2009;144(4):524-530.
23. Geisler CH, Kolstad A, Laurell A, et al. Nordic MCL2 trial update: six-year follow-up after intensive immunochemotherapy for untreated mantle cell lymphoma followed by BEAM or BEAC + autologous stem-cell support: still very long survival but late relapses do occur. Br J Haematol. 2012;158(3):355-362.

24. Delarue R, Haioun C, Ribrag V, et al. CHOP and DHAP plus rituximab followed by autologous stem cell transplantation in mantle cell lymphoma: a phase 2 study from the Groupe d'Etude des Lymphomes de l'Adulte. Blood. 2013;121(1):48-53.

25. Dreyling M, Lenz G, Hoster E, et al. Early consolidation by myeloablative radiochemotherapy followed by autologous stem cell transplantation in first remission significantly prolongs progressionfree survival in mantle-cell lymphoma: results of a prospective randomized trial of the European MCL Network. Blood. 2005;105(7): $2677-2684$

26. Vandenberghe E, Ruiz de Elvira C, Loberiza FR, et al. Outcome of autologous transplantation for mantle cell lymphoma: a study by the European Blood and Bone Marrow Transplant and Autologous Blood and Marrow Transplant Registries. Br J Haematol. 2003;120(5): 793-800.

27. Peterlin P, Leux C, Gastinne T, et al. Is ASCT with TBI superior to ASCT without TBI in mantle cell lymphoma patients? Transplantation. 2012;94(3):295-301.

28. Leitch HA, Gascoyne RD, Chhanabhai M, Voss NJ, Klasa R, Connors JM. Limited-stage mantle-cell lymphoma. Ann Oncol. 2003;14(10):1555-1561.

29. Bernard M, Tsang RW, Le LW, et al. Limited-stage mantle cell lymphoma: treatment outcomes at the Princess Margaret Hospital. Leuk Lymphoma. 2013;54(2):261-267.

30. Pott C, Hoster E, Delfau-Larue MH, et al. Molecular remission is an independent predictor of clinical outcome in patients with mantle cell lymphoma after combined immunochemotherapy: a European MCL intergroup study. Blood. 2010;115(16):3215-3223.

31. Kluin-Nelemans HC, Hoster E, Hermine O, et al. Treatment of older patients with mantle-cell lymphoma. $N$ Engl J Med. 2012;367(6): $520-531$.

32. Rummel MJ, Niederle N, Maschmeyer G, et al. Bendamustine plus rituximab versus CHOP plus rituximab as first-line treatment for patients with indolent and mantle-cell lymphomas: an openlabel, multicentre, randomised, phase 3 non-inferiority trial. Lancet. 2013;381(9873):1203-1210

33. Bauwens D, Maerevoet M, Michaux L, et al. Activity and safety of combined rituximab with chlorambucil in patients with mantle cell lymphoma. Br J Haematol. 2005;131(3):338-340.

34. Ghielmini M, Schmitz SF, Cogliatti S, et al. Effect of single-agent rituximab given at the standard schedule or as prolonged treatment in patients with mantle cell lymphoma: a study of the Swiss Group for Clinical Cancer Research (SAKK). J Clin Oncol. 2005;23(4): 705-711.

35. Rosenbluth BD, Yahalom J. Highly effective local control and palliation of mantle cell lymphoma with involved-field radiation therapy (IFRT). Int J Radiat Oncol Biol Phys. 2006;65(4):1185-1191.

36. Rummel MJ, Al-Batran SE, Kim SZ, et al. Bendamustine plus rituximab is effective and has a favorable toxicity profile in the treatment of mantle cell and low-grade non-Hodgkin's lymphoma. J Clin Oncol. 2005;23(15):3383-3389.

37. Weide R, Feiten S, Friesenhahn V, et al. Retreatment with bendamustine-containing regimens in patients with relapsed/refractory chronic lymphocytic leukemia and indolent B-cell lymphomas achieves high response rates and some long lasting remissions. Leuk Lymphoma. Epub December 5, 2012.

38. Weide R, Hess G, Koppler H, et al. High anti-lymphoma activity of bendamustine/mitoxantrone/rituximab in rituximab pretreated relapsed or refractory indolent lymphomas and mantle cell lymphomas. A multicenter phase II study of the German Low Grade Lymphoma Study Group (GLSG). Leuk Lymphoma. 2007;48(7): 1299-1306. 
39. Thomas DW, Owen RG, Johnson SA, et al. Superior quality and duration of responses among patients with mantle-cell lymphoma treated with fludarabine and cyclophosphamide with or without rituximab compared with prior responses to CHOP. Leuk Lymphoma. 2005;46(4):549-552.

40. Forstpointner R, Dreyling M, Repp R, et al. The addition of rituximab to a combination of fludarabine, cyclophosphamide, mitoxantrone (FCM) significantly increases the response rate and prolongs survival as compared with FCM alone in patients with relapsed and refractory follicular and mantle cell lymphomas: results of a prospective randomized study of the German Low-Grade Lymphoma Study Group. Blood. 2004;104(10):3064-3071.

41. Forstpointner R, Unterhalt M, Dreyling M, et al. Maintenance therapy with rituximab leads to a significant prolongation of response duration after salvage therapy with a combination of rituximab, fludarabine, cyclophosphamide, and mitoxantrone (R-FCM) in patients with recurring and refractory follicular and mantle cell lymphomas: Results of a prospective randomized study of the German Low Grade Lymphoma Study Group (GLSG). Blood. 2006;108(13):4003-4008.

42. Visco C, Finotto S, Zambello R, et al. Combination of rituximab, bendamustine, and cytarabine for patients with mantle-cell nonhodgkin lymphoma ineligible for intensive regimens or autologous transplantation. J Clin Oncol. 2013;31(11):1442-1449.

43. Inwards DJ, Fishkin PA, Hillman DW, et al. Long-term results of the treatment of patients with mantle cell lymphoma with cladribine (2-CDA) alone (95-80-53) or 2-CDA and rituximab (N0189) in the North Central Cancer Treatment Group. Cancer. 2008;113(1):108-116.

44. Fisher RI, Bernstein SH, Kahl BS, et al. Multicenter Phase II study of bortezomib in patients with relapsed or refractory mantle cell lymphoma. J Clin Oncol. 2006;24(30):4867-4874.

45. O'Connor OA, Moskowitz C, Portlock C, et al. Patients with chemotherapy-refractory mantle cell lymphoma experience high response rates and identical progression-free survivals compared with patients with relapsed disease following treatment with single agent bortezomib: results of a multicentre Phase 2 clinical trial. $\mathrm{Br} J$ Haematol. 2009;145(1):34-39.

46. Moreau P, Pylypenko H, Grosicki S, et al. Subcutaneous versus intravenous administration of bortezomib in patients with relapsed multiple myeloma: a randomised, phase 3, non-inferiority study. Lancet Oncol. 2011;12(5):431-440.

47. Weigert $\mathrm{O}$, Weidmann E, Mueck R, et al. A novel regimen combining high dose cytarabine and bortezomib has activity in multiply relapsed and refractory mantle cell lymphoma-long-term results of a multicenter observation study. Leuk Lymphoma. 2009;50(5):716-722.
48. Witzig TE, Geyer SM, Ghobrial I, et al. Phase II trial of single-agent temsirolimus (CCI-779) for relapsed mantle cell lymphoma. J Clin Oncol. 2005;23(23):5347-5356.

49. Ansell SM, Inwards DJ, Rowland KM Jr, et al. Low-dose, single-agent temsirolimus for relapsed mantle cell lymphoma: a Phase 2 trial in the North Central Cancer Treatment Group. Cancer. 2008;113(3): 508-514.

50. Hess G, Herbrecht R, Romaguera J, et al. Phase III study to evaluate temsirolimus compared with investigator's choice therapy for the treatment of relapsed or refractory mantle cell lymphoma. J Clin Oncol. 2009;27(23):3822-3829.

51. Witzig TE, Vose JM, Zinzani PL, et al. An international phase II trial of single-agent lenalidomide for relapsed or refractory aggressive B-cell non-Hodgkin's lymphoma. Ann Oncol. 2011;22(7):1622-1627.

52. Habermann TM, Lossos IS, Justice G, et al. Lenalidomide oral monotherapy produces a high response rate in patients with relapsed or refractory mantle cell lymphoma. Br J Haematol. 2009;145(3): 344-349.

53. Cook G, Smith GM, Kirkland K, et al. Outcome following ReducedIntensity Allogeneic Stem Cell Transplantation (RIC AlloSCT) for relapsed and refractory mantle cell lymphoma (MCL): a study of the British Society for Blood and Marrow Transplantation. Biol Blood Marrow Transplant. 2010;16(10):1419-1427.

54. Friedberg JW, Sharman J, Sweetenham J, et al. Inhibition of Syk with fostamatinib disodium has significant clinical activity in non-Hodgkin lymphoma and chronic lymphocytic leukemia. Blood. 2010;115(13): 2578-2585

55. Morschhauser F, Seymour JF, Kluin-Nelemans HC, et al. A Phase II study of enzastaurin, a protein kinase $\mathrm{C}$ beta inhibitor, in patients with relapsed or refractory mantle cell lymphoma. Ann Oncol. 2008;19(2): 247-253.

56. Burger JA, Buggy JJ. Emerging drug profiles: Bruton tyrosine kinase (BTK) inhibitor ibrutinib (PCI-32765). Leuk Lymphoma. Epub February 21, 2013.

57. Advani RH, Buggy JJ, Sharman JP, et al. Bruton tyrosine kinase inhibitor ibrutinib (PCI-32765) has significant activity in patients with relapsed/ refractory B-cell malignancies. J Clin Oncol. 2013;31(1):88-94.

58. Wang ML, Rule S, Martin P, et al. Targeting BTK with ibrutinib in relapsed or refractory mantle-cell lymphoma. $N$ Engl J Med. Epub June 19, 2013.
Clinical Interventions in Aging

\section{Publish your work in this journal}

Clinical Interventions in Aging is an international, peer-reviewed journal focusing on evidence-based reports on the value or lack thereof of treatments intended to prevent or delay the onset of maladaptive correlates of aging in human beings. This journal is indexed on PubMed Central, MedLine, the American Chemical Society's 'Chemical Abstracts Ser-

\section{Dovepress}

vice' (CAS), Scopus and the Elsevier Bibliographic databases. The manuscript management system is completely online and includes a very quick and fair peer-review system, which is all easy to use. Visit http://www.dovepress.com/testimonials.php to read real quotes from published authors. 